\title{
ENSINO OBRIGATÓRIO: “PRUDENTE É ESPERAR-SE DO TEMPO O PRECISO REMÉDIO"
}

\author{
Cíntia Borges de Almeida \\ Universidade do Estado do Rio de Janeiro, Brasil \\ Dimas Santana Souza Neves \\ Universidade do Estado de Mato Grosso, Brasil \\ José Gonçalves Gondra \\ Universidade do Estado do Rio de Janeiro, Brasil
}

$\cos 80$

\begin{abstract}
Resumo
Neste trabalho procuramos debater o tema da obrigatoriedade do ensino em Minas Gerais e Mato Grosso, províncias que procuraram normatizar essa medida desde a primeira metade do século 19. Com isso, ancoramos o estudo nas contribuições dos estudos comparados e na análise dos discursos dos relatórios dos presidentes de uma província do sudeste e uma do oeste do Brasil. Por se tratar do exame de uma medida de alcance global, voltada para as multiplicidades, a pesquisa buscou dialogar com a concepção de governamentalidade, considerando o tema da escola obrigatória como necessidade e urgência voltada para gestão e homogeneização da população.

Palavras-chave: obrigatoriedade do ensino, Minas Gerais, Mato Grosso.
\end{abstract}

\section{COMPULSORY EDUCATION: "IT IS PRUDENTE TO EXPECT THE PRECISE REMEDY FROM THE TIME”}

\begin{abstract}
In this current work, we sought to discuss the issue of compulsory education in Minas Gerais and Mato Grosso, Provinces that sought to standardize this step since the first half of the nineteenth century. With this, we will anchor the current study of contributions from comparative studies and discourse analysis of the chairmen's reports of a southeastern province and one in western Brazil. Because this fact is taking a measure of global reach, so, the current work is focused on the multiplicities. The research sought dialogue with the conception of governmentality, considering the
\end{abstract}


subject of compulsory education as a necessity and urgency facing management and homogenization of the population.

Key-words: compulsory education, Minas Gerais, Mato Grosso.

\section{ENSEÑANZA OBLIGATORIA: "PRUDENTE ES ESPERAR DEL TIEMPO EL PRECISO REMEDIO"}

\section{Resumen}

En este trabajo buscamos debatir el tema de la obligatoriedad de la enseñanza en Minas Gerais e Mato Grosso, Provincias que buscaron normar esa medida desde la primera mitad del siglo 19. Con eso, basamos el estudio en las contribuciones de los estudios comparados y en el análisis del discurso de informes de los presidentes de una provincia del sudeste y una del oeste del Brasil. Por tratarse del examen de una medida de alcance global, dirigida para las multiplicidades, la investigación buscó dialogar con la concepción de gubernamentalidad, considerando el tema de la escuela obligatoria como necesidad y urgencia dirigida para la gestión y homogeneización de la población.

Palabras-clave: obligatoriedad de la enseñanza, Minas Gerais, Mato Grosso.

\section{ENSEIGNEMENT OBLIGATOIRE: “PRUDENTE EST ATTENDEZ DU TEMPS LE PRECISE REMĖDE"}

\section{Résume}

Dans ce étude, nous examinons la question de la scolarité obligatoire dans les Provinces de Minas Gerais et de Mato Grosso, provinces qui cherchaient à uniformiser cette mesure depuis la première moitié du 19e siècle. Avec cela, nous ancrons l'étude basés sur les contributions des études comparatives et l'analyse du discours des rapports des présidents de deux provinces; une du sud-est et une autre d'ouest du Brésil. Parce qu'elle est une mesure de portée mondiale, centrée sur les multiplicités, l'investigation a cherché le dialogue avec le concept de la gouvernementalité, considérant l'objet de l'enseignement obligatoire comme une nécessité et urgence face à gestion et l'homogénéisation de la population.

Mots-clé: l'enseignement obligatoire, Minas Gerais, Mato Grosso.

perspectiva dos estudos comparados aponta para a busca de sentidos
comuns entre experiências distintas, bem como para o reconhecimento
das especificidades entre o que se processa nas cidades, estados, países. Partindo deste princípio, neste estudo, analisamos o tema da obrigatoriedade da instrução primária a partir das representações produzidas por diversos agentes sociais, em especial, os que ocupavam posições destacadas na gestão da aparelhagem pública nas províncias de Minas Gerais e Mato Grosso ao longo do século 19.

Para explorar a hipótese do ensino compulsório como uma medida de governo, uma estratégia do Estado voltada para aprofundar o projeto de sociedade moderna e de nação civilizada, buscamos reunir e indagar alguns discursos dos presidentes provinciais, de 
inspetores e outros sujeitos envolvidos no projeto educacional, a partir da primeira lei mineira e mato-grossense pelas quais se procurou institucionalizar a obrigatoriedade, nos anos de 1835 e 1837, respectivamente. Com esse investimento, procuramos observar e compreender a dinâmica dos sistemas educacionais, ou de aspectos a eles relacionados, devendo ser pensada como um produto de uma história e de uma sociedade em movimento, possível de ser evidenciado por meio do exercício de comparação interprovincial.

De acordo com Ferreira (2008), é possível compreender o surgimento da educação comparada em um contexto histórico em que a expansão escolar e a afirmação da ciência se constituíam como pilares fundamentais do progresso, exatamente para poder contribuir com reformas educativas mais fundamentadas, como as que se processam nas duas províncias aqui estudadas. Para Ferreira,

a leitura dos aspectos comuns e das diferenças relativas a uma problemática fornece informações mais interessantes que as resultantes de uma leitura dessa mesma problemática num só contexto. A comparação em educação gera uma dinâmica de raciocínio que obriga a identificar semelhanças e diferenças entre dois ou mais fatos, fenômenos ou processos educativos e a interpretá-las levando em consideração a relação destes com o contexto social, político, econômico, cultural, etc. a que pertencem. Daí a necessidade de outros dados, da compreensão de outros discursos. (Idem, p. 125)

Deste modo, não se trata de justapor informações, elencar semelhanças e diferenças no que se refere ao instituto da obrigatoriedade, mas de tentar apanhar o dispositivo em construção e funcionamento, associado, por sua vez, às dinâmicas locais, ainda que o mesmo apareça revestido de uma suposta universalidade e invariância.

\section{Remediar os males sociais}

Ao final do século 20 e início do 21, a escola brasileira passou e passa por uma incessante discussão em torno da sua obrigatoriedade, dos níveis do ensino e suas funções sociais. Desde a consideração de que a escolarização obrigatória deveria recobrir o ensino fundamental, compreendendo o atendimento das crianças cujas idades estejam entre 6 e 14 anos, portanto, sem contemplar a educação infantil e o ensino médio, como também exclui-se desse propósito a educação de jovens e adultos, dentre outras modalidades de ensino, levando a questionar o caráter facultativo da escolarização para esses segmentos e modalidades do sistema de ensino.

Para atender esse segmento da população, constitui-se uma malha complexa e heterogênea da chamada educação de jovens e adultos. No entanto, na exterioridade do 
princípio da obrigatoriedade, o que garantiria a oferta da educação escolar para esse contingente? Dependeria da iniciativa, compromisso e boa vontade de que agentes sociais? Como se pode observar, este é um ponto relevante, pois assinala que o debate sobre a obrigatoriedade é uma questão aberta em nosso tempo ${ }^{1}$.

Por meio de alguns estudos a respeito do tema da obrigatoriedade, é possível perceber que há muito tempo ele se encontra presente na arena dos debates educativos, mediante a exigência da escolarização por parte do poder público e imposição da educação obrigatória às famílias e crianças.

A questão do direito à educação e seu caráter compulsório foram engendrados em meio aos novos processos de regulação social, como a medicalização e a judicialização da vida escolar, imprimindo novos desafios ao direito educacional, no qual a escola foi representada (e ainda representa) um espaço de formação física, moral e intelectual e, ao mesmo tempo, uma instituição marcada pelo caráter de prevenção social.

A circulação de idéias sobre a necessidade da ampliação do acesso à escolarização das diversas camadas da população deve ser entendida como partícipe de conjunto de medidas associadas ao processo civilizatório, presente em diferentes países desde meados do século 18, que envolve um sem-número de investimentos, fenômeno observável pela multiplicidade de instrumentos ou meios que visavam promover algo que podemos definir como domesticação ou civilização do humano.

Como um projeto tipicamente humanista, o processo civilizatório representa uma marca da modernização das sociedades o que, em linhas bem gerais, envolveria uma profunda mudança comportamental, um investimento na promoção do controle social e do autocontrole do indivíduo sobre si mesmo ${ }^{2}$. Com isso, se pode observar a existência de múltiplas e estreitas relações entre os ideais civilizatórios, a mudança das condutas e a formação de uma noção de nação.

De acordo com Michel Foucault (1994), "o que é significativo é a maneira pela qual a revolução se faz espetáculo, é a maneira pela qual ela é acolhida em torno dos espectadores que não participam, mas que olham, que assistem e que, ou bem ou mal, se deixam arrastar por ele" (p. 5). O referido espetáculo parece ter servido de motivação, de entusiasmo para outras nações ou ainda, pode, em outros casos, servido como camuflagem para cobrir e dar legitimidade a outras práticas e projetos sociais, o que nos sugere pensar no modelo e na sua força institucionais, mas também nos usos e

\footnotetext{
${ }^{1}$ A respeito da expansão da obrigatoriedade de oito para nove anos, ver Gondra (2010).

${ }^{2}$ O processo civilizador, do sociólogo Nobert Elias, é uma referência incontornável sobre este complexo processo, no qual se vê um claro destaque da mudança de hábitos e costumes, sobretudo acerca das funções corporais, assim como da disseminação da noção de previdência e de autocontrole.
} 
experiências que favorece. Chave fértil para refletir a respeito da adoção da obrigatoriedade no Brasil, como manifestado pelo presidente da Província de Minas Gerais:

Um dos maiores erros que tem cometido nossos estadistas, com notável detrimento do país, é certamente terem transplantado para o nosso Império instituições, que com quanto sejam profícuas à sociedade em geral e se compadeçam com as circunstâncias de povos já provectos na marcha da civilização, não são com tudo adaptadas á um país como o nosso, jovem ainda na civilização e existência política e, por isso, ainda fraco em recursos para competir com a robustez da Europa culta. (Rego, 1851, p. $\mathrm{S} 1-5)^{3}$

Esse fragmento permite pensar o acolhimento do espetáculo analisado por Foucault. Ainda que no Brasil "não [fossem] oferecidos meios pelo público", e fossem "insuficientes" os recursos para "transplantar" as idéias para se promover uma educação civilizada, ainda assim, foram muitas as tentativas de "dar consciência" 4 à população. Era interessante trazer para o cenário do projeto de nação em curso as referências ao mundo culto como alternativa para justificar e imprimir legitimidade às ações governamentais.

Neste caso, a instrução da população consiste em uma das emergências para afirmação e expansão do Estado e a obrigatoriedade do ensino o mecanismo, o dispositivo de governo capaz de cumprir essa tarefa e funcionar como o remédio para a ignorância popular.

Em certo sentido, a educação passou a ser entendida como uma forma que, por excelência, podia fazer cumprir os ideais supracitados. Assim, a ela foi atribuído um papel significativo nesse movimento, de tal modo que vimos surgir, "os princípios liberais da educação: a educação como um dever do Estado; a educação como laica e livre; a obrigatoriedade e a gratuidade do ensino elementar" (Leão, 2008, p. 73).

Considerando esse conjunto de elementos, procuramos tomar distância dos procedimentos generalistas e universalizantes para, com um investimento de outra ordem, em outra escala, tentar compreender algumas particularidades do projeto educacional oitocentista a partir da análise das experiências de Minas Gerais e Mato Grosso.

\section{O caso das terras mineiras}

No caso de Minas Gerais, o incentivo à expansão do ensino em geral, como o processo de escolarização, foi impulsionado no período pós-independência (Faria Filho;

\footnotetext{
${ }^{3}$ Relatório pronunciado à Assembléia Legislativa de Minas Gerais pelo Presidente José Ricardo de Sá Rêgo, em 1851, no qual o mesmo justifica as causas do atraso da instrução.

${ }^{4}$ Os termos destacados por aspas ao longo do texto são expressões retiradas dos relatórios dos presidentes das Províncias de Minas Gerais e Mato Grosso, consultados para elaboração deste estudo.
} 
Sales, 2009). A lei promulgada em 28 de março de 1835, lei n.13, junto ao seu regulamento, o n. 3, definem importantes medidas para a educação na Província, entre elas, a imposição da obrigatoriedade do ensino e a criação da escola normal para a formação dos professores primários ${ }^{5}$.

A lei n.13, tida como a primeira legislação a prever a obrigatoriedade do ensino ou ensino compulsório, foi amplamente discutida. Ela e o seu regulamento n. 3, do mesmo ano, "eram um conjunto articulado e detalhado de determinações que instituía e regulava uma verdadeira política de instrução para a Província" (Gonçalves; Faria Filho, 2004, p. 160). Seu artigo $1^{\circ}$ considerava a existência de dois graus para a instrução primária, ensinando-se, no primeiro, a ler, escrever e prática das quatro operações aritméticas; e no segundo, as mesmas matérias, sendo a aritmética até as proporções e, também, noções gerais dos deveres morais e religiosos.

O art. $12^{\circ}$ impunha, para o ensino do $1^{\circ} \mathrm{grau}$, que os pais de família se obrigassem de dá-lo a seus filhos, ou nas escolas públicas, particulares, ou em suas próprias casas, sendo punidos por esta falta com uma multa de $10 \$$ a $20 \$ 000$ réis, dobrando os valores na reincidência. A obrigação imposta pelo art. $12^{\circ}$ aos pais estendia às crianças de oito aos 14 anos de idade.

Essa mesma lei também assinalava a responsabilidade dos professores em fiscalizar o cumprimento da matrícula e freqüência. No entanto, segundo os relatórios dos presidentes da Província mineira, a normalização prevista não se processou nos termos do ordenamento jurídico. Não somente a população infringiu a lei, como também a transgrediram os próprios agentes responsáveis pela instrução.

No relatório de $1840^{6}$, ao lado da sugestão de se adotar o método simultâneo como pedagogia oficial, indica-se, igualmente, a passagem das atribuições dos delegados para as Câmaras e para o Conselho Local, a criação de uma inspetoria da instrução pública e, por último, "que os artigos da Lei n.13, relativos às multas que os pais sofreriam por não darem instrução primária aos filhos, se tornassem exequíveis e reais" (Veiga, 1840, p. XLIV-XLV).

O registro, ao mesmo tempo em que indica que é possível pensar a obrigatoriedade enquanto uma estratégia de controle da população, oferece um sinal de que a mesma não estava sendo cumprida. Primeiramente o presidente Bernardo J. Veiga aborda a necessidade do método simultâneo, pista de um deslocamento em relação ao método

\footnotetext{
${ }^{5}$ A respeito da obrigatoriedade do ensino em Minas Gerais e na Corte, ver Gondra e Faria Filho (2007). Para o caso de Minas Gerais e, de modo especial, Juiz de Fora, bem como na Província de Buenos Aires, ver Almeida (2012).

${ }^{6}$ Relatório do presidente Bernardo Jacintho da Veiga, 1840.
} 
oficial previsto na Lei Geral de Ensino de 15 de outubro de 1827. No entanto, esse é um detalhe da reforma metodológica em curso posto que, em sua descrição, se pode observar um forte interesse no regime disciplinar proporcionado pelo novo método do que, propriamente, na sua possibilidade de ampliar o atendimento e mesmo em sua eficiência em termos de instrução.

Em segundo lugar, ao reorganizar a inspetoria, de modo a atribuir funções de inspeção à municipalidade e ao Conselho Local, a fiscalização poderia se processar de modo mais próximo e mais intenso. Por último, o presidente exigia o cumprimento da aplicação das multas, evidenciando a inércia nesta matéria e reforçando seu relevo.

$\mathrm{Na}$ continuidade dos debates a respeito dessa matéria em Minas Gerais e a observação das questões destacadas nos documentos, em 1844, por exemplo, o presidente José S. d'Andrea denuncia a ilusão da obrigatoriedade, denunciando o descompromisso das famílias e a prática dos professores "de burlar os mapas de matrícula e freqüência”.

Como pelas leis mineiras devem ser abolidas as escolas que não tiverem ao menos 24 discípulos são obrigados os chefes de família a mandarem seus filhos às escolas, e tem os mestres gratificações além dos ordenados, segundo o numero dos discípulos que as freqüentam: tudo se arranja muito bem. Os pais matriculam os filhos e não os mandam à escola; e os mestres enchem as suas relações de nomes de indivíduos que existem sim, mas que nunca lhes entram em casa, e põem-Ihes os dias de freqüência que bem lhes parece. (D’andréa, 1844, p. 28)

Como se pode observar, com esse diagnóstico, o dirigente mineiro indica os vetores da política a ser seguida, de modo a fazer com que a instrução pudesse funcionar como um instrumento a serviço do projeto de civilização da população, como "alicerce primordial de nossa civilização" (Motta, 1862) ${ }^{7}$. Neste caso, a obrigatoriedade do ensino deveria atuar como um dispositivo de segurança ${ }^{8}$ capaz de agir em favor dos ideais de governo ${ }^{9}$, de controlar o cumprimento das técnicas de disciplina e moralização, apontadas como

${ }^{7}$ Discurso pronunciado à Assembléia Legislativa de Minas Gerais pelo terceiro vice-presidente Joaquim Camillo Teixeira da Motta, em 1862.

8 Por dispositivos/mecanismos de segurança entendemos ser técnicas de governo que possibilitam uma série de vigilâncias, controles, olhares, ainda que de forma dissimulada, embora preventiva. As técnicas não se restringem mais às leis ou correções. Pensa-se também, em formas diagnósticas, espaços de segurança, tratamento do aleatório, normalização da segurança, correlação entre técnicas e população (Foucault, 2008).

${ }^{9}$ Quanto à noção foucaultiana de governo, ela tem, para expressá-lo de alguma maneira, dois eixos: o governo como relação entre sujeitos e o governo como relação consigo mesmo. No primeiro sentido, ele é um conjunto de ações sobre ações possíveis [...], ele é sempre uma maneira de atuar sobre um ou vários sujeitos atuantes, e isso na medida e que atuam ou são suscetíveis de atuar [...]. Governar consiste em conduzir condutas [...]. No segundo sentido, é também da ordem do governo a relação que se pode estabelecer consigo mesmo na medida em que, por exemplo, se trata de dominar os prazeres ou os desejos (Castro, 2004, p.190). 
"elementos de ordem e obstáculo contra o crime e necessidade social (Alvim; Bretas; Andrade, 1865, p. A 18)"10.

Nesta linha, cabe associar o instituto da obrigatoriedade ao conceito de governamentalidade ${ }^{11}$, pois o mesmo se constitui em instrumento potente para se pensar algumas ações do Estado, sobretudo aquelas orientadas para as multiplicidades do tecido social. Uma orientação que pode ser percebida na manifestação dos professores mineiros, de 1865. Para eles, "em geral a satisfação das necessidades individuais é provada pelo indivíduo, mas ao Estado cumpre prover a satisfação das necessidades sociais (Idem, 1865)".

Esses professores de Juiz de Fora observam a intervenção estatal tanto pelo seu caráter econômico quanto pelo jurídico, pois, segundo eles, "corr[eu] ao Estado o dever de vigiar [a instrução] garantindo ao cidadão brasileiro o direito à instrução e fez do ensino uma obrigação do poder público" já que a mesma "t[inha] importância política, civil e industrial" (Ibidem, 1865).

Nas intenções do Estado incluía-se o desejo de aperfeiçoar e defender a sociedade. Para tanto, era necessário cuidar da instrução de modo que os ensinamentos propostos também pudessem agir fora dos espaços escolares: nas casas, nas ruas, nos diversos espaços das cidades. A criança dentro da faixa etária de instrução obrigatória que freqüentasse o ensino particular, doméstico, público, transmitiria os saberes escolarizados junto aos demais integrantes do seu grupo social. Assim, na função de divulgadora, de propagadora da instrução e dos hábitos de higiene e disciplina legitimados por intermédio da experiência escolar, o governo da infância passou a assumir um papel importante na sociedade.

Os discursos acerca da necessidade da instrução da infância e da obrigatoriedade como estratégia de governo caminhavam no sentido do pensamento da formação do bom homem social, sendo o ensino primário "uma condição de moralidade e bons costumes, de modo que sua difusão por todas as classes importa uma garantia à segurança individual e à ordem pública" (Vasconcelos, 1881, p. 37) ${ }^{12}$.

De acordo com Gondra (2000), os diferentes discursos acerca da instrução comprometidos com o projeto civilizatório, fossem eles associados ao campo médico,

\footnotetext{
${ }^{10}$ Relatório dos inspetores José Cesário de Faria Alvim, Rodrigo José Ferreira Bretas e Ovídio João Paulo. Andrade, no ano de 1865. Agentes comissionados pelo presidente Pedro d'Alcântara Cerqueira Leite para dar parecer sobre o estado da instrução pública.

11 O tema da governamentalidade, em todas as suas formas, pode ser descrito em torno de três questões fundamentais, conforme exposto por Foucault: "como se governar, como ser governado, como fazer para ser o melhor governante possível” (2007, p. 277).

12 Fala dirigida à Assembléia Legislativa de Minas Gerais na sessão ordinária do ano de 1881, pelo presidente João Florentino Meira de Vasconcelos.
} 
político, religioso ou pedagógico, entre outros, convergiam no sentido de entender a infância instruída pela via da escola como instrumentos de divulgação das exigências necessárias para o bem-estar da sociedade. No caso dos médicos higienistas, de modo geral, compartilhavam da defesa de

uma educação pública que subtraísse a criança da influência única e exclusiva do ambiente familiar, posto que o Estado queria marcar seu filhos, educando-os. O Império desejava constituir seus súditos, não mais cabendo, portanto, uma educação exclusivamente doméstica, em que as mães cuidassem da formação moral e os pais, da formação intelectual. Defendia, contra esse formato, uma educação em que a família se constituísse em torno da criança [...] o que alteraria o próprio conceito de família e o lugar da educação no seu interior. Defende, do mesmo modo, que a educação não se esgotasse nesse novo modelo de funcionamento familiar, sustentando a necessidade de uma educação pública a ser desenvolvida sob os auspícios da higiene. (p.109)

O deslocamento sugerido da casa para a escola pode ser compreendido no âmbito de um investimento maciço voltado para o ordenamento da vida em sociedade, para a construção de projetos comuns. É, pois, nesse movimento que se nota a remissão regular à idéia de cidadania nos relatórios dos presidentes, quando afirmavam que a instrução era a "garantia dos direitos individuais", "as raízes do mal" e da "injustiça", "necessária para os conhecimentos humanos" e para a "liberdade", "a luz contra as trevas", a "defensora da democracia".

Nesses discursos, muitas vezes, é possível identificar traços que apontam para uma tentativa de controle da população, seja de seu comportamento e conduta, seja de seus possíveis atos em relação à sociedade, segurança nacional e consigo mesmo.

Um indício desta disposição pode ser observado no relatório do presidente Manoel J. G. Rebello. Para ele, era preciso combater a frouxidão das disposições que existiam, de modo que ninguém "t[inha] o direito de não aprender" como "os pais não t[inham] o direito entre a educação e a ignorância" (1878, p. 29-30). A preocupação não deveria se circunscrever ao bem estar e o direito dos indivíduos, mas deveria lidar os riscos que parte dessa população "incivilizada" e "indisciplinada" oferecia à sociedade.

Os discursos presentes nos relatórios dos presidentes da província mineira, como por exemplo, a fala do inspetor geral do ensino Joaquim Barbosa da Silva, anunciavam a instrução popular e a obrigatoriedade como emergência do Estado, considerando sua dimensão estratégica:

[Sobre a baixa-freqüência] uma das causas que contribuem para este resultado é, sem dúvida, a inexequibilidade do ensino primário obrigatório [...]. Prover de remédios a essa indiferença é tarefa facílima, desde que os cidadãos queiram auxiliar o Governo neste objeto. Basta atenderem que a 
instrução primária [...] é principalmente uma condição de moralidade e de bons costumes, de modo que sua difusão por todas as classes importa uma garantia à segurança individual e à ordem pública (Silva, 1881, p.37). À instrução popular está preso indissoluvelmente o futuro político e econômico do país [...]. Nenhuma reforma porém, entre nós, será profícua sem que se atenda, principalmente, à constituição do magistério e ao alargamento do ensino obrigatório. $(1883, \text { p. } 10)^{13}$

Pensar na instrução pública obrigatória se refere a um projeto em que a aprendizagem da leitura, escrita, cálculo, religião oficial, história e geografia pátria se articulava com programas sociais de alcances e finalidades variados. A ação do Estado, pela instrução pública, como efeito correlato, almejava a inserção das multiplicidades em um campo normativo e disciplinar, pois se fazia necessário atentar para a participação dos sujeitos nos projetos sociais, como nos diz o $3^{\circ}$ vice-presidente Joaquim C. T. Motta, ao iniciar seu relatório pronunciado à Assembléia Legislativa atribuindo à instrução o papel de "elemento indispensável do desenvolvimento da indústria" e "garantia suprema das instituições" (1862, p.18), chamando atenção para as utilidades desse serviço, considerando sua função social e econômica, bem como a formação de acordo com os preceitos dos que assumiam postos de direção dos diferentes aparelhos do Estado.

Como procuramos demonstrar, a questão da obrigatoriedade do ensino se constitui em uma constante nos discursos, assim como um ponto bastante recorrente na legislação mineira que visava a organizar a instrução. Sua presença também não se limitou a lei de 1835. Outras experiências de reformas foram apresentadas, como o regulamento n. 28 , de 10 de janeiro de 1854, autorizado pela lei n.516; a lei n. 1064, de 4 de outubro de 1860; a lei n. 2476 de, 9 de novembro de 1878; a lei n. 2892, de 6 de novembro de 1882; no regulamento n. 100, de 14 de dezembro de 1883, entre outros que também aparecem citados nos relatórios enquanto reformas na organização da instrução pública, na formação do magistério, nas funções e denominações dos diferentes cargos relacionados à inspeção escolar e fiscalização do ensino primário, como indicados nos fragmentos que se seguem:

O regulamento n. 28 de 10 de janeiro do corrente ano, autorizado pela lei n. 516, veio em boa hora curar os males de que se recentia a instrução pública e particular da província de Minas Gerais [...]. A fiscalização do ensino [...] passou por consideráveis melhoramentos. (Vasconcellos, 1854, p. S4-3) ${ }^{14}$

\footnotetext{
${ }^{13}$ Fala dirigida à Assembléia Legislativa de Minas Gerais na sessão ordinária do ano de 1883, pelo presidente da província Antônio Gonçalves Chaves.

${ }^{14}$ Relatório apresentado pelo presidente Francisco Diogo Pereira de Vasconcellos na passagem de administração ao vice-presidente José Lopes Silva Vianna, em 1854.
} 
[Sobre a lei n. 1064], pouco exigente quanto às habilitações dos candidatos ao professorado, entretanto além das escolas publicas criadas em virtude da mesma, em todas as freguesias da província, ainda facilita a criação de outras [...] permitindo mais a concessão de licenças a indivíduos que quiserem ensinar particularmente. Esta facilidade da lei tem produzido o funesto resultado da multiplicidade de escolas. (Alvim; Bretas; Andrade, 1865 , p. 29$)^{15}$

Convencidos de que se faziam precisas reformas no regulamento n. 84 [...] organizei o regulamento n. 100 [...]. Quanto à inspeção, criei a fiscalização extraordinária do governo por agentes diretos e convictos de que a liberdade do ensino não pode ser tão absoluta que exclua o interesse e direito que [...] tem os poderes públicos na difusão da instrução, estabeleci fiscalização harmônica com a liberdade [...]. Ampliando as disposições do regulamento n.84 sobre o ensino obrigatório, o novo regulamento aplica ao fundo escolar. (Chaves, 1883, p. 11) ${ }^{16}$

Partindo do entendimento de que esses enunciados não representam a totalidade e complexidade das experiências a que se referem, procuramos agregar informações distintas daquelas que aparecem em alguns estudos no campo da história da educação que descrevem o período imperial como um período praticamente nulo no que se refere às experiências educacionais.

Os debates a respeito da questão da obrigatoriedade possibilitam desmistificar essa representação do Império, pois apresentam pensamentos, idéias, políticas educacionais regulamentadas e projetadas a partir da iniciativa estatal e de muitas outras iniciativas particulares. Ao analisarmos a obrigatoriedade nesses documentos, observamos que várias medidas estiveram entrelaçadas com esse dispositivo como, por exemplo, a necessidade da criação das escolas normais para a formação de professores primários e a constituição de um corpo de fiscais para assegurar a efetividade da norma:

O povo despreza a instrução porque não freqüenta as escolas, e o corpo docente, ou por negligência no desempenho de seus deveres, ou por absoluta incapacidade intelectual não preenche os fins do magistério público. Aumentar a freqüência das escolas, depurar o magistério de professores incapazes são dois problemas para cuja solução há um meio em que por vezes, temos insistido: organizar-se em bases sólidas a inspeção do ensino. (Silva, 1881, p. A-57)

O corpo normativo produzido procurou regulamentar mudanças sobre essas questões, como a lei de $1^{\circ}$ de outubro de 1828 , que já atribuía à fiscalização a garantia para a promoção do ensino ${ }^{17}$, e o artigo $10^{\circ}$ da lei n. 2892 , de 1882 , que suprimiu os lugares de inspetores de círculos literários e delegou suas funções aos inspetores municipais. Muitos arranjos, criações e supressões foram propostos com vistas à uma

\footnotetext{
${ }^{15}$ Idem a nota 8.

16 Idem a nota 11.

${ }^{17}$ Fala do $2^{\circ}$ vice-presidente Joaquim José de Sant'Anna, em 1882.
} 
organização efetiva dos serviços de instrução, de modo que pudessem vir a cumprir a tarefa de civilizar a população.

Diferente do que é possível observar nos relatórios dos presidentes da província durante o Império, os relatórios dos primeiros anos republicanos, de 1890 a 1895, apresentam informações reduzidas acerca da educação. Nos primeiros, podemos observar passagens reduzidas sobre a educação agrícola, industrial, superior e os liceus e praticamente nenhuma informação sobre a situação da instrução primária. No relatório de 1894 encontramos algumas informações sobre a lei n. 41, do ano de 1892, e justificativas a respeito da imprecisão do censo de 1890, embora não constem detalhes e nenhuma estatística sobre o mesmo.

Esse apontamento favorece o questionamento a respeito das transformações processadas no âmbito educacional na passagem do Império para a República. Se antes os relatórios abordavam de modo constante a necessidade de um projeto escolar e de uma organização no ensino primário e normal, o mesmo não aconteceu no início republicano, conforme consta nos relatórios dos dirigentes de Minas Gerais. As dezenas de páginas dedicadas à instrução primária nos anos anteriores foram reduzidas a poucas unidades ou se tornaram ausentes nos relatórios da década de 1890. O que isso nos faz pensar? Qual a importância da instrução no projeto de nação? Ou seria o contrário, essa ausência nos aponta sobre os interesses do governo? O que de inovador trouxe esses discursos para caracterizar o Império como atrasado e a República como propositora de novos ideais como alguns estudos sugerem pensar?

Nesse primeiro momento, reduzindo nossos olhares aos anos iniciais do período republicano, diríamos que não identificamos as inovações anunciadas. Como registrado no próprio relatório e ao esclarecer o programa para o ensino normal proposto pela nova lei, "só depois de alguns anos se poderá tirar ilações da conveniência ou desnecessidade de modificar-se o sistema adotado" (Penna, 1894, p. 12) ${ }^{18}$.

Os discursos não se constituem em verdades absolutas, tampouco devem ser considerados como transparência ou decalque do real, cabendo ao historiador interrogar os materiais com que opera, tomando distância da vontade e capacidade de julgar na medida em que tal procedimento não se coaduna com a ação dos historiadores (Bloch, 2001). Partimos da análise dos materiais das províncias de Minas Gerais e Mato Grosso para tentar construir uma reflexão a respeito de um dispositivo geral experimentado em situações específicas.

\footnotetext{
${ }^{18}$ Mensagem do presidente do Estado de Minas Gerais Affonso Augusto Moreira Penna, em 1894.
} 
Para efeitos desse estudo, postulamos o discurso como algo regulado, construído e construtor de identidades sociais, como um mecanismo de interpelação, de convencimento, um modelo social carregado de intencionalidades, produzido em situações singulares. Nesse registro, consideramos que os documentos trabalhados contêm elementos que ajudam a esclarecer o sentido da institucionalização do ensino obrigatório pelo Estado, bem como aspectos do próprio jogo da enunciação.

Apontada como um ato extremo, como o último recurso a ser adotado para garantir a instrução, a obrigatoriedade também foi representada como o remédio e o único meio capaz de garantir a civilização. Esse tipo de enunciado possibilita pensar que a instrução estava entrelaçada a uma idéia de desenvolvimento, logo, a obrigatoriedade atuaria como um dispositivo a favor da ordem e do progresso.

Além disso, em face da crença nas ilimitadas potencialidades da escola, que caracterizou os ambientes culturais e políticos ocidentais do século 19 (Nóvoa, 1994), a escola se vê articulada de modo incontornável à indicadores do mundo civilizado, como se pode observar nos debates e iniciativas voltadas para afirmação da escola e da função decisiva exercida pelo dispositivo da obrigatoriedade escolar em uma das regiões mais escolarizadas do Brasil. O movimento complementar para testar essa hipótese foi constituir como ponto de observação uma das regiões mais afastadas e menos escolarizadas do Brasil, isto é, a região do Mato Grosso.

\title{
O caso das terras pantaneiras
}

\begin{abstract}
O ensino primário obrigatório tem dado bons resultados em muitos países, especialmente na grande República Norte-Americana; e pensam alguns que muito concorre para o atraso da instrução o não se ter ainda feito efetiva a disposição do artigo 27 do Regulamento, que decreta o ensino obrigatório. E será exequível entre nós semelhante disposição? (Ferreira, 1887 , p. 44$)^{19}$
\end{abstract}

No fim do século 19, o presidente da Província de Mato Grosso teceu algumas considerações a respeito da obrigatoriedade, indagando sobre a exequibilidade do princípio. Ainda que se referisse ao modelo norte-americano e aos resultados decorrentes da aplicação do instituto da obrigatoriedade do ensino primário, esta era uma questão pendente em Mato Grosso. Deste modo, a autoridade procurou recolocar em debate um dos mais importantes, polêmicos e instigantes princípios da educação: a obrigatoriedade do ensino.

\footnotetext{
${ }^{19}$ Relatório do presidente da Província de Mato Grosso, doutor Joaquim Ramos Ferreira, em $1^{\circ}$ de setembro de 1887.
} 
Portanto, a citação ajuda a compreender o tema como questão incontroversa legalmente, isto é, como uma matéria já estabelecida pelas experiências dos outros e pela normatização produzida localmente. Porém, a realidade exigia outras considerações em torno do assunto e dos modos de regulamentação e aplicação, o que leva a indagar a respeito das motivações, condições de prática, articulações entre instituições para definição das responsabilidades, os imbróglios que a definição criou, as questões polêmicas, os desafios da afirmação, aplicação e os procedimentos tomados para a deliberação e efetivação do dispositivo em Mato Grosso ${ }^{20}$.

$\mathrm{Na}$ continuidade de sua exposição, o próprio dirigente alertava que

os filhos do proletário, como sabeis, começam bem cedo a auxiliar seus pais em suas fainas diárias, e quando mesmo estes possam dispensar o seu auxílio poderão fazer a necessária despesa com vestuário, calçado, livros, papel, etc. E por ventura poderá a Província suprir gratuitamente de calçado, livros, etc., os meninos que tiverem condições de receber a instrução primária, e não puderem fazê-la pela extrema pobreza de seus pais. Não; a disposição do artigo 27 será por muito tempo ainda letra morte entre nós. (idem, 1887, p. 44)

O doutor Joaquim possuía uma representação da complexidade da questão. Em sua compreensão, a escola compulsória era uma questão que envolvia a definição das responsabilidades da família, o papel do Estado, as condições de existência dos sujeitos escolarizáveis e as relações com o mundo do trabalho. Desde a questão da situação social da criança, passando pela necessidade do trabalho até a manutenção das necessidades pessoais, familiares e educativas, o presidente da Província procurou apontar os desafios provocados por tal deliberação, que não pode ser circunscrito à Província de Mato Grosso, nem ao século 19.

Ao levar estas questões em consideração, podemos compreender que as idéias em torno da escolarização obrigatória se encontravam bastante articuladas com outros modos de legitimar a instrução na sociedade brasileira. Neste texto, optamos pela necessidade de compreender que, ao menos, a idéia de obrigatoriedade estava relacionada com o papel do Estado, com as responsabilidades da família, dialogando

${ }^{20} \mathrm{O}$ debate deve inscrever os temas da gratuidade, universalidade e liberdade de ensino, para se poder compreender a constituição de um "regime de verdades" que procurou construir uma determinada forma escolar por meio das reformas da instrução pública desde 1854. Como se pode perceber, este modo de pensamento tinha por finalidade primordial fazer com que a instrução chegasse às instituições e aos indivíduos, que transformasse pessoas, definisse obrigações, permitisse, estimulasse e facilitasse o acesso e permanência na instituição escolar, inclusive, que apontasse os caminhos possíveis de saída, como o caso da jubilação de professores e encaminhamento de alunos de um grau a outro de ensino e expulsão dos mesmos. Afinal, esse era um conjunto que permitiu aos dirigentes montar o "esqueleto", ou o "shysthema", como diziam a época, da organização social ou a forma escolar como pensou Vincent et all (2001). Enfim, essas orientações incentivaram setores sociais e o governo a definirem o rosto da escola pública brasileira. 
igualmente com os pressupostos relativos ao exercício da liberdade. Ao destacar os discursos oficiais, procuramos indicar a questão da obrigatoriedade como medida complementar de controle da população, posto que se caracteriza como uma medida global, voltada para o conjunto da população.

Ao analisar o regime de verdades em torno da escola produzido na sociedade matogrossense no século 19, podemos perceber que os discursos tentavam conduzir para determinados sentidos de vida social, conforme demonstrado no estudo de Neves (2009). Nesse aspecto, minimizavam o efeito da individualidade para organizar ações voltadas para o governo das coletividades, sem, contudo, eliminar a classificação e a competição entre sujeitos da escolarização. Nessa direção, podemos entender a idéia de obrigatoriedade do ensino como parte de um conjunto que visava produzir uma forma escolar primária que recobrisse o conjunto, isto é, que se constituísse em experiência inevitável para todos.

Os manifestos e posições em torno do princípio da obrigatoriedade do ensino primário assemelham-se à imposição do serviço militar obrigatório ${ }^{21}$, associado às idéias de patriotismo, nacionalismo, obediência à autoridade e fortalecimento da ordem coletiva, condição, inclusive, para o exercício de outras funções no serviço público. No caso da ausência da vacina, tal evidência impedia o sujeito de se matricular e freqüentar a escola, exigindo que fosse considerado um sujeito vacinado, conforme se encontra definido em regulamentos da Corte Imperial e de diversas províncias, dentre as quais a de Mato Grosso, no ano de 1872.

É nesse quadro que procuramos compreender a emergência da obrigatoriedade do ensino em Mato Grosso, tentando demonstrar as singularidades presentes nos processos de constituição de uma política pública. Assim, no Mato Grosso, desde a primeira metade do século 19, é possível observar a produção de discursos que afirmam a necessidade da criação das condições para efetivação da obrigatoriedade do ensino ${ }^{22}$. Mas, antes que os discursos fossem intensificados, os dirigentes locais providenciaram instrumentos que comprovassem a necessidade da obrigatoriedade. Primeiro, o recurso às estatísticas em torno da freqüência escolar.

21 Outra medida semelhante se refere à obrigatoriedade da vacinação. Neste caso, talvez seja mais evidente o caráter profilático e preventivo, ainda que também estejam presentes na obrigatoriedade do serviço militar e escolar.

${ }^{22} \mathrm{O}$ primeiro regulamento da instrução pública de Mato Grosso, denominado de Lei Provincial n. 8 de 5 de maio de 1837 já havia disposto, em seu artigo $4^{\circ}$, o controle efetivo sobre o contingente de escolares, estabelecendo números como condição para a continuidade da existência da escola e também prescrito nos artigos 32 a 37 a obrigatoriedade da escolarização, inclusive estipulando valores das multas e condições de aplicação. Há que se considerar que inexistia pena de prisão aos pais. 
O inspetor Gaudie Ley, em 1851, havia detectado que tanto a escola particular, por distrair as crianças, como o pai por se negar a levar os filhos à instituição de ensino, exigiam a aplicação da obrigatoriedade escolar.

Diversos relatórios, das décadas de 1850 e 1860, atestavam os índices de freqüência escolar como um modo do controle da quantidade de crianças presentes no processo educativo de determinadas escolas. A exigência era de um controle tanto das escolas públicas quanto das instituições particulares de ensino ${ }^{23}$.

As considerações em torno do assunto são instigantes, como podemos perceber no relatório encontrado no APMT, na caixa 1859. Esse documento foi apresentado pelo inspetor geral dos Estudos, Joaquim Gaudie Ley ao presidente da Província, Antônio Pedro de Alencastro, em Cuiabá, no dia 27 de fevereiro de 1860.

A indicação do inspetor geral orientava para concessão de benefícios e não para execução de penalidades. Apesar de prevista, os dirigentes não se referiam a multas, muito menos da possibilidade da prisão. Ao contrário, procurava conceder "mais alguma proteção aos alunos pobres", compreendendo que a instrução não era somente uma “divida social para o povo", mas uma "necessidade pública” (Ley, 1860).

As décadas de 1870 e 1880 podem ser consideradas como um tempo no qual as idéias em torno da escolarização e, particularmente, a respeito da obrigatoriedade do ensino na Província de Mato Grosso são retomadas e atualizadas. Esse fenômeno se processa pela ação de letrados, mas também pela ação dos inspetores de ensino e presidentes de província ${ }^{24}$, tempo que também foi marcado pela guerra.

Considerando o envolvimento com a Guerra do Paraguai, as lutas dos dirigentes se voltavam para superar o conflito e criar melhores condições de vida para a sociedade mato-grossense. Pelos relatórios constata-se, dentre as alternativas, a proposta de ampliação da escolarização, aplicação das multas e preocupação com o ensino feminino e doméstico:

A Lei Paroquial de 5 de maio de 1837, procurando remediar isto dispôs o seguinte: que os coletores constrangerão aos pais a mandarem à escola os seus filhos de 8 a 15 anos sob pena da multa anual de $6 \$ 000$ réis

23 "O que da a razão de 1:42 habitantes computados as populações indígena e escrava, e de 1:20 somente a livre" (Relatório apresentado pelo inspetor geral dos Estudos, Joaquim Gaudie Ley, ao presidente da Província, Antônio Pedro de Alencastro. Cuiabá, 27 de fevereiro de 1860. APMT, caixa 1859).

${ }^{24}$ Além da permanência de Joaquim Gaudie Ley por mais de 20 anos na inspetoria da instrução, esse período é marcado também pela presença de médicos e de padres que assumem essa pasta e produzem significativas obras em torno do tema educação [...] como o caso mais proeminente do padre Ernesto Camilo Barreto, considerado um dos mais destacados intelectuais daquela modernidade matogrossense. Além desse clérigo havia nessa década a presença também do sr. José de Miranda Reis, do presidente da Província Hermes Ernesto da Fonseca [...], do sr. Manuel José Murtinho e, ao final desse periodo, a presença do dr. Dormevil J. S. Malhado. 
tirados da terça de seus bens! Entretanto, autorizou ao Governo da Província a dispensar aos pais desta obrigação desde que mostrassem falta de meios [...]. No meu entender, o remédio não está na imposição de penas de semelhante natureza, mas sim em criarem-se incentivos e facilidades que convidem aos pais a mandarem seus filhos à escola [...] e sobretudo na melhor retribuição dos mestres para que estes, tomando amor a sua profissão, dediquem-se exclusivamente ao magistério[...] Não se pode negar o grande atraso em que ainda jaz entre nós a primeira educação dos meninos. Seja por causa da escravidão [...] ou tenha este mal outras causas, o que é certo é que convém remediar este estado de causas, pois além dos males que para a sociedade acarreta a ignorância [...]. Os pais, a quem ordinariamente ocupam tantos deveres externos, quase nunca podem dirigir os primeiros passos de seus filhos, que ficam por isso entregues aos cuidados das mães e muitas vezes das escravas, e da ignorância e vícios destas nascem os defeitos que mais tarde vem a ser um constante motivo de desgostos. É por isso que hoje é opinião incontestada que da boa educação do sexo feminino, criando-se por elas as boas mães de família, depende a educação da mocidade [...]. Prudente é esperar-se do tempo o preciso remédio. (Ley, 1870, p. $56 \mathrm{~V}$ a $64 \mathrm{~V})^{25}$

Em relatório de 1871, enviado ao presidente da Província, o padre Ernesto Camilo Barreto procurou reforçar o tom dos discursos da época. Começou afirmando que "[naquele momento havia] um anelo unânime; uma aspiração ardente, um desejo fervoroso: o de esclarecer o espírito", pois, na visão do inspetor "por toda parte o anelo transparec[ia], a aspiração sobressa[ia], o desejo impera[va]".

Uma vez que para este padre e agente estatal havia uma busca pela sabedoria, pois o rico, o proletário, o plebeu, o homem, a mulher "corr[iam] para os mananciais puros e cristalinos, todos procura[vam] o novo Jordão, a fim de receber o segundo batismo da instrução, indispensável a todas as classes, a todos os estados e em todas as condições da vida" (Barreto, 1871, p. 9).

O discurso de caráter profético procurava se sustentar pelos conhecimentos que demonstrava possuir em torno do tema instrução. Empenhado na formulação do "preciso remédio", Ernesto Camilo convocou os demais dirigentes para as mudanças que deveriam ser promovidas, pois na sua concepção "[era] mister dissipar as sombras que a ignorância projeta[va]. [Era] mister que o presente [fosse] o corolário do futuro. [Era] mister semear hoje para colher amanhã". Em seguida, o mesmo assegurou que "o Regulamento de 30 de setembro de 1854 [era] um verdadeiro anacronismo [naqueles] dias [...]. Assim pensando, resolv[eu] logo dar alguns passos, no sentido de reformar o mencionado regulamento" (Idem, 1871, p. 25).

A reforma para ser profícua deve[ria] ser completa e radical ainda que inserida nas possibilidades e limites orçamentários. Com essa concepção, investiu na reforma da

${ }^{25}$ Relatório do inspetor geral dos Estudos Joaquim Gaudie Ley ao vice-presidente da Província Luís da Silva Prado. Cuiabá, 20 de abril de 1870 (APMT - livro 227, p 56 V a 64 V). 
instrução que ganhou forma com o Regulamento de 1873, tornando-se um dos instrumentos normativos mais instigantes do período provincial em Mato Grosso.

No entanto, em 1875, o padre-inspetor continuou a reclamar da inobservância do princípio da obrigatoriedade escolar prevista no regulamento de 1873 . Não se tratava de ausência de ordenamento jurídico, mas de sua execução:

O regulamento de 1873, atendendo a essa conveniência, estabeleceu as multas, mas estas são improfícuas, já porque, como disse, muitas escolas se abrem e fecham sem conhecimento das Inspetorias; já porque a penalidade imposta só serve para abrir conflitos em que a chicana e a política tomam parte com o fim de desprestigiarem e anarquizarem as mais salutares medidas e às autoridades incumbidas de executá-las. (Idem, 1876$, p. 9$)^{26}$

No inicio da década de 1880, o relatório do dr. Dormevil J. S. Malhado retomava a questão da instrução obrigatória. O administrador acreditava que "os povos modernos t[inham] ocupado constantemente da instrução que alumi[ava] o espírito, porque conheceram que não se imprim[ia] na consciência do homem regras do bem viver sem lhe esclarecer a inteligência, ampliar-lhe as idéias, instruí-lo enfim”.

Por isso, "para aqueles que o esquec[iam], ou por ignorância ou capricho não o cumpr[iam], criou-se leis para coagi-los a esse dever, originando-se daí a instrução obrigatória" (Malhado, 1880, p. 7). Trata-se de uma demonstração adicional relacionada às medidas propostas e executadas pelo Estado que recoloca a necessidade de se promover o constrangimento legal, tomando por base um sistema punitivo a que pais e famílias deveriam ser submetidas para assegurar o sucesso do processo de escolarização.

Como outros dirigentes, o dr. Dormevil também apresentou a situação da educação obrigatória em outros países, como na Alemanha, Prússia de Frederico $2^{\circ}$, Estados Unidos da América, Inglaterra, Bélgica, França e Portugal. Segundo o entendimento do inspetor geral, esses países reconheciam a importância da instrução e para essa autoridade e "o Brasil não podia ficar estacionário perante o triunfo solene obtido por uma idéia que vai tendo geral aceitação; assim no Rio de Janeiro, Pernambuco, e creio que em Minas e Bahia, decretou-se a instrução obrigatória” (idem, idem, p. 7).

Portanto, a obrigatoriedade escolar deveria ser convertida em uma questão estratégica para o bom funcionamento do Estado brasileiro:

O novo Regulamento obriga os pais a darem educação a seus filhos; mas podem fazê-lo livremente sem o menor receio de violência. Porém ao que

\footnotetext{
${ }^{26}$ APMT - Microfilme 1876 (anexo 2). Relatório apresentado pelo inspetor geral dos Estudos, pe. Ernesto Camilo Barreto, ao presidente da Província, Hermes Ernesto da Fonseca. Cuiabá, 8 de abril de 1876.
} 
se nega cumprir este dever imposto pelas leis divinas, defraudando a sociedade e roubando-lhe um membro provavelmente útil, a lei impõe penas, que devem ser tanto mais severas, quanto maior for a rebeldia do pai ou educador desnaturado. (Idem, 1880, p. 7$)^{27}$

Ao final do documento a autoridade desejou que a população pudesse reconhecer as boas intenções do presidente da Província, tentando dividir a população entre aqueles que conduziam os filhos à escola, mesmo em escolas particulares, e aqueles que deixavam de levar seus filhos à instituição de ensino. Estes últimos eram descritos como sujeitos que deveriam ser objeto de ação proporcional à rebeldia.

Um dos discursos mais incisivos da obrigatoriedade do ensino foi difundido pelo presidente da Província em $1882^{28}$. Ao solicitar a execução da medida prescrita no regulamento, o governante assegurou que a "obrigatoriedade do ensino já [era] na província um preceito legal, mas não t[inha] passado de uma teoria escrita para simples advertência aos pais de família pelo grave erro que comet[iam] condenando a prole à ignorância". Diante das circunstâncias apelou para o imperativo de tornar a medida efetiva, pois em suas considerações disse que "conhe[cia] e respeit[ava] os direitos do homem na sociedade, mas desconhe[cia] o direito à ignorância" (Alencastro, 1882, p. 19).

Para o dirigente, o não cumprimento da obrigatoriedade estava ligado à idéia de que os pais ficavam ofendidos no seu "direito discricionário que ainda se atribu[iam] sobre os filhos" (idem) ${ }^{29}$. Portanto, a luta estava travada na relação entre o poder disciplinar do Estado e a soberania da família:

A família, na medida em que obedece a um esquema não disciplinar, a um dispositivo de soberania, é a articulação, o ponto de engate absolutamente indispensável ao próprio funcionamento de todos os sistemas disciplinares. Quero dizer que a família é a instância de coerção que vai fixar permanentemente os indivíduos aos aparelhos disciplinares [...]. É porque a família existe [...], que a obrigação escolar age e que as crianças, enfim os indivíduos, essas singularidades somáticas são fixadas e por fim individualizadas no interior do sistema escolar. Para ser obrigatório ir à escola tem de agir também esta outra soberania que é a soberania da família. (Foucault, 2006, p. 100)

${ }^{27}$ Relatório apresentado pelo diretor geral da Instrução Pública, dr. Dormevil José dos Santos Malhado ao presidente da Província de Mato Grosso, barão de Maracaju. Cuiabá, 17 de agosto de 1880.

${ }^{28}$ Relatório com que o exmo. sr. coronel dr. José Maria de Alencastro, presidente da Província de Mato Grosso abriu a $1^{a}$ sessão da $24^{a}$ legislatura da respectiva Assembléia, no dia 15 de junho de 1882.

${ }^{29}$ A tática discursiva que elegeu primou por colocar em confronto o poder da família, a escola estatal e o poder dos governantes, até porque o ensino como responsabilidade do Estado já era tema legalmente incontroverso na maneira em que estava definido pela Constituição Federal outorgada em 1824. Entretanto, é preciso perceber que a questão agora passava do debate em torno da "mal entendida liberdade" para a idéia do "poder discricionário" da família em relação ao envio dos filhos à escola pública. 
Como se pode observar, a obrigatoriedade consiste em um princípio, cuja efetividade exige uma recomposição das forças e competências do Estado e da casa. Para que a norma funcionasse de acordo com a previsão, se fazia necessário convencer e contar com a adesão da família. Para tanto, ao lado da longa campanha em favor da escola primária compulsória, procurou-se ampliar a difusão dos equipamentos escolares de modo a permitir aproximação entre escolas e famílias.

Foi dessa maneira, alertando para os perigos e fazendo propaganda do dispositivo, que o debate em torno da obrigatoriedade de escolarização se processou em Mato Grosso, como se pode perceber uma vez mais no relatório de 1884. Neste documento, o barão de Batovi, então presidente da Província procura explicar a situação da escolarização:

Homens que vivem de pequena lavoura, trabalhando com seus próprios braços, porque em geral não os podem ser pagos, aproveitam aqueles habitantes o serviço dos filhos, desde que estes atingem a idade escolar [...]. O meio único de remover este mal era a execução do sistema do ensino obrigatório, já estatuído no regulamento vigente de 4 de março de 1880. (Batovi, 1884, p. 56)

Novamente, o tema das condições sociais da população foi retomado com a finalidade de explicar a baixa freqüência escolar e, concomitantemente, justificar a necessidade de atendimento por parte do poder estatal. Assim, ponderava em favor dos filhos que ajudavam no trabalho doméstico e na manutenção econômica da família partilhando os labores e deixando os estudos em segundo plano.

Em um dos últimos relatórios de dirigentes do Império, o padre Ernesto Camilo produziu uma longa consideração em torno da importância da escola e do processo de escolarização ${ }^{31}$. Abdicar da prisão, desprezar a punição, desistir das multas, eis as propostas formuladas para se promover outras possibilidades de convencimento da população para o cumprimento da obrigatoriedade do ensino.

Ainda que o santelmo para superação da baixa freqüência escolar fosse o ensino obrigatório, as propostas deixaram de vislumbrar a aplicação de prisão e até mesmo da multa. Apelava-se, no caso, para a compreensão da situação das crianças, da pobreza dos pais e a impossibilidade de se resolver a questão apoiada no argumento da capacidade orçamentária:

${ }^{30}$ Relatório com que o exmo. general barão de Batovi, presidente da Província de Mato Grosso, abriu a $1^{\text {a }}$ sessão da $25^{\mathrm{a}}$ legislatura da respectiva Assembléia, no dia $1^{\circ}$ de outubro de 1884 .

${ }^{31}$ Relatório apresentado ao presidente da Província, gal. Hermes Hernesto da Fonseca, pelo inspetor geral dos Estudos, pe. Ernesto Camilo Barreto. Cuiabá, 13 de abril de 1877. APMT, microfilme rolo 1876-1880. 
O sistema de ensino obrigatório pede despesas superiores à receita da província [...]. Fechemos [...] todas as válvulas por onde possam respirar a incúria dos educadores, a indolência natural da infância e a criminosa condescendência dos pais. (Barreto, 1877, p. 12) ) $^{32}$

A idéia era então tomar providências legais, administrativas e econômicas para que o processo de escolarização tomasse o sentido de evitar que as crianças abandonassem as escolas antes da habilitação, isto é, antes dos exames anuais. Ao se perceber os limites na execução do princípio da obrigatoriedade escolar, indicavam-se outras medidas voltadas para lidar com a incúria dos educadores e famílias indolentes.

\section{Considerações finais}

A instrução da população em faixa etária definida como escolar pode ser observada através de justificativas que correspondiam aos interesses estratégicos de governo. Neste caso, a gestão do múltiplo, do ignorante e do plástico parece convergir para a infância, foco da ação escolar. Nesse sentido,

a manutenção da infância em discurso ocorre, portanto, com a agregação de novos elementos. Ao lado da economia, a defesa da sociedade, mais do que a defesa das individualidades das crianças, é eleita como razão para a proteção da infância. Ameaça ou presságio adjetivam os excluídos, aspectos que fundamentam a intervenção do Estado, qualificando o problema da infância ora como questão do Estado, ora como magno problema social. (Gondra, 2000, p. 106)

Sendo assim, entendemos a instrução popular e o ensino compulsório como ações de governo voltadas para atender uma emergência de Estado e da sociedade moderna, uma medida associada à idéia de bom governo. Como procuramos observar, nas duas experiências analisadas neste trabalho, o caráter obrigatório do ensino primário se encontra fundado e legitimado pela tentativa de governar os corpos e as populações. Trata-se, portanto, de uma tentativa voltada para moldar as condutas, de disciplinar corpos, inculcar saberes, de estabelecer um uso regular do tempo e de proporcionar a aprendizagem de inúmeras hierarquias e exclusões proporcionadas pela experiência da escolarização.

As proposições e as deliberações relativas ao instituto da obrigatoriedade escolar presentes nas formações discursivas aqui analisadas auxiliaram na formação de um conjunto discursivo que se fortaleceu e ganhou adeptos com a finalidade de efetivar a construção do projeto civilizador da sociedade com vistas a proporcionar a construção de uma população educada e ordenada, como procuramos demonstrar com base no estudo

\footnotetext{
${ }^{32}$ Idem.
} 
dos casos da província mais escolarizada do século 19 e de uma das menos escolarizadas.

\section{Referências}

ALMEIDA, Cintia Borges. Entre a tyramnya cruel e a pedra fundamental: a obrigatoriedade do ensino primário como uma técnica de governo em Minas Gerais. Rio de Janeiro: Uerj, 2012. 284f. Dissertação (Mestrado em Educação). Programa de PósGraduação em Educação, Universidade do Estado do Rio de Janeiro.

BLOCH, Marc. Apologia da história ou o ofício do historiador. Rio de Janeiro: Jorge Zahar, 2001.

CASTRO, Edgardo. Vocabulário de Foucault: um percurso pelos seus temas, conceitos e autores. Belo Horizonte: Autêntica, 2004.

ELIAS, Norbert. O processo civilizador: formação do estado e civilização. Rio de Janeiro: Jorge Zahar, 1993.

ELIAS, Norbert. O processo civilizador: uma história dos costumes. Rio de Janeiro: Jorge Zahar, 1994.

FARIA FILHO, Luciano Mendes de; SALES, Zeli Efigênia Santos de. Escolarização da infância brasileira: a contribuição do Bacharel Bernardo Pereira de Vasconcelos. In: FARIA FILHO, Luciano Mendes de (org.). Políticos, literatos, professoras, intelectuais: o debate público sobre educação em Minas Gerais. Belo Horizonte: Mazza, 2009, p. 21-44.

FARIA FILHO, Luciano Mendes de; GONÇALVES, Irlen Antônio. Processo de escolarização e obrigatoriedade escolar: o caso de Minas Gerais (1835-1911). In: FARIA FILHO, Luciano Mendes de (org.). A infância e sua educação: materiais, práticas e representações. Belo Horizonte: Autêntica, 2004.

FERREIRA, Antonio Gomes. O sentido da educação comparada: uma compreensão sobre a construção de uma identidade. Educação, Porto Alegre, v. 31, n. 2, 2008, p. 124138.

FOUCAULT, Michel. Em defesa da sociedade: curso no Collège de France (1975-1976). São Paulo: Martins Fontes, 1999.

FOUCAULT, Michel. Governamentalidade. In: Microfísica do poder. Rio de Janeiro: Graal, 2007, p. 278-293.

FOUCAULT, Michel. O poder psiquiátrico. São Paulo: Martins Fontes, 2006.

FOUCAULT, Michel. Qu'est-ce que lês lumières? In: Dits et écrits. Paris: Gallimard, 1994, p. 679-688.

FOUCAULT, Michel. Segurança, território e população: curso no Collège de France (1977-1978). São Paulo: Martins Fontes, 2008.

GONDRA. José Gonçalves. A sementeira do porvir: higiene e infância no século 19. Educação e Pesquisa, São Paulo, v. 26, n. 1, 2000, p. 99-117.

GONDRA. José Gonçalves; FARIA FILHO, Luciano Mendes. In the name of civilization: compulsory education and cultural politics in Brazil in the 19th century. In: Imported modernity in post-colonial state formation: the apropriation of political, educational and cultural models in nineteenth-century Latin America. Frankfurt: Peter Lang, 2007, p. 307337. 
GONDRA, José Gonçalves. ¿Gobierno de los otros? Expansión del tiempo escolar y obligatoriedad de la enseñanza en Brasil. Revista Educación y Pedagogía, v. 22, 2010, p. 37-50.

LEÃO, Andreza Marques de Castro. A influência do lluminismo nas políticas educacionais atuais: em pauta a cidadania. Diversa, ano 1, n. 2, 2008, p. 64-89.

NEVES, Dimas Santana Souza. Razões de Estado: as reformas da instrução pública em Mato Grosso, Minas Gerais e na Corte Imperial (1851-1859). Rio de Janeiro: Uerj, 2009. 658f. Tese (Doutorado em Educação). Programa de Pós-Graduação em Educação, Universidade do Estado do Rio de Janeiro.

NÓVOA, Antônio. História da educação. Lisboa: Faculdade de Psicologia e de Ciências da Educação, 1994.

\section{Arquivo público de Mato Grosso /APMT}

Lata 1866 D, n.23, 1866.

Microfilme 1876, anexo 2, 1876.

Microfilme rolo $1876-1880,1880$.

University of Chicago. Center for Research Libraries. Brazilian Government Document Digitization Project. Ministerial Reports. Disponível em: <http://brazil.crl.edu/bsd/bsd/hartness/predpub.html>. Acesso em: 11 dez. 2010.

CÍNTIA BORGES DE ALMEIDA é mestre em Educação pela Universidade do Estado do Rio de Janeiro - Uerj.

Endereço: Rua Joaquim Távora 14/201 - 20950-380 - Rio de Janeiro - RJ Brasil.

E-mail: cintiaborgesalmeida@yahoo.com.br.

DIMAS SANTANA SOUZA NEVES é professor de História da Educação na Universidade do Estado de Mato Grosso - Unemat.

Endereço: Rua dos Espinhais, 18, Cavalhada 2 - 78200-000 - Cáceres - MT Brasil.

E-mail: dimasneves14@ig.com.br.

JOSÉ GONÇALVES GONDRA é professor de História da Educação na Universidade do Estado do Rio de Janeiro - Uerj, pesquisador do CNPq e da Faperj.

Endereço: Rua Olegário Mariano, 276 - 20510-210 - Tijuca - Rio de Janeiro Rio de Janeiro - Brasil.

E-mail: gondra.uerj@gmail.com. 